\title{
logurte simbiótico sabor cajá (Spondias \\ Mombin L.): características físico-químicas, microbiológicas e de aceitabilidade
}

\section{Symbiotic yogurt flavor cajá (Spondias Mombin L.): physical- chemical, microbiological and acceptability characteristics}

\author{
Lívia Cabanez Ferreira', Lívia Muritiba Pereira de Lima Coimbra² (D), \\ Naylanne Lima de Sousa ${ }^{2 *}$ (1), Ellen Mila Cutrim Maciel$^{2}$, Alda Verônica Souza Livera ${ }^{3}$, \\ Celiane Gomes Maia da Silva ${ }^{4}$
}

${ }^{1}$ Associação Educacional de Ciências da Saúde, Faculdade Pernambucana de Saúde (FPS), Departamento de Nutrição, Recife/PE - Brasil

${ }^{2}$ Universidade CEUMA, Departamento de Nutrição, São Luís/MA - Brasil

${ }^{3}$ Universidade Federal Rural de Pernambuco (UFRPE), Departamento de Nutrição, Recife/PE - Brasil

${ }^{4}$ Universidade Federal Rural de Pernambuco (UFRPE), Departamento de Pós-graduação em Ciência e Tecnologia de Alimentos, Recife/PE - Brasil

*Corresponding Author: Naylanne Lima de Sousa, Universidade CEUMA, Departamento de Nutrição, Rua Josué Montello, 01, Renascença II, CEP: 65075-120, São Luís/MA - Brasil, e-mail: naylannelima@gmail.com

Cite as: Ferreira, L. C., Coimbra, L. M. P. L., Sousa, N. L., Maciel, E. M. C., Livera, A. V. S., \& Silva, C. G. M. (2021). Symbiotic yogurt flavor cajá (Spondias Mombin L.): physical-chemical, microbiological and acceptability characteristics. Brazilian Journal of Food Technology, 24, e2019111. https://doi.org/10.1590/1981-6723.11119

\begin{abstract}
Resumo
O objetivo do trabalho foi avaliar os parâmetros físico-químicos, microbiológicos e a aceitabilidade de iogurtes funcionais, com e sem suplementação de frutooligossacarídeos, sabor cajá. Elaborou-se quatro formulações de iogurte, sendo elas: duas com leite integral com e sem suplementação de frutooligossacarídeos e duas com leite desnatado com e sem suplementação de frutooligossacarídeos. Foram analisados os valores de $\mathrm{pH}$, acidez titulável, sólidos solúveis, padrões microbiológicos de qualidade, contagem de bactérias lácticas totais e análise sensorial, na qual foram realizadas perguntas sobre frequência de consumo, conhecimento dos benefícios relacionados ao consumo de produtos lácteos fermentados, intenção de compra e índice de aceitabilidade. Quanto ao $\mathrm{pH}$, a formulação elaborada com leite integral e frutooligossacarídeos apresentou diferença significativa $(p<0,05)$ em relação às demais formulaç̃̃es. Não houve diferenças significativas $(p>0,05)$ quanto à acidez titulável e sólidos solúveis. A contagem de bactérias lácticas totais demonstrou valores elevados que atendem aos parâmetros da legislação. As formulações apresentaram qualidade higiênico-sanitária satisfatória e foram bem aceitas pelos consumidores para todos os atributos avaliados no teste sensorial. Assim, apresentaram-se viáveis em termos sensoriais, físico-químicos e microbiológicos, com potencial aproveitamento pela população por possuírem características simbióticas benéficas à saúde.
\end{abstract}

Palavras-chave: Probióticos; Simbióticos; logurte; Alimentos funcionais; Produtos lácteos; Tecnologia de alimentos. 


\begin{abstract}
This work aimed to evaluate the physicochemical, microbiological parameters and acceptability of functional yogurt, with and without fructooligosaccharide supplementation, flavor yellow mombin . Four yogurt formulations were elaborated: two with whole milk with and without fructooligosaccharide supplementation, and two with skimmed milk with and without fructooligosaccharide supplementation. It was evaluated the formulations' $\mathrm{pH}$, titratable acidity, soluble solids, microbiological quality standards, total lactic acid bacteria count, and sensory analysis. Questions were asked about frequency of consumption, knowledge of the benefits related to the consumption of fermented dairy products, purchase intention and acceptability index. Regarding $\mathrm{pH}$, the formulation made with whole milk and fructooligosaccharides showed significant difference $(p<0.05)$ compared to the other formulations. It was observed no significant differences $(p>0.05)$ regarding titratable acidity and soluble solids. The total lactic bacteria count has shown high values that meet the parameters of the legislation. The described formulations of satisfactory hygienic and sanitary quality were well accepted by consumers for all sensory detection tests, being viable in sensory, physicochemical and microbiological terms, with potential use by the population for its symbiotic characteristics and health benefits.
\end{abstract}

Keywords: Probiotics; Symbiotics; Yoghurt; Functional foods; Dairy products; Food technology.

\title{
1 Introdução
}

O frequente consumo de alimentos como o iogurte é reconhecidamente benéfico para a manutenção da saúde. Esse efeito é atribuído, em parte, às bactérias ácido-lácticas utilizadas na elaboração do produto e dotadas de propriedades terapêuticas (Das et al., 2019).

Probióticos são definidos como "[...] microrganismos vivos que, quando consumidos em quantidades adequadas, conferem benefícios à saúde do hospedeiro" (Brasil, 2018).

Prebióticos são carboidratos não digeríveis que afetam beneficamente o indivíduo pela estimulação seletiva do crescimento e/ou da atividade de uma ou de número limitado de espécie(s) de bactérias no cólon (Langa et al., 2019).

Um dos métodos mais utilizados para potencializar as propriedades funcionais dos alimentos é a adição de culturas probióticas e/ou fibras prebióticas. A adição de probióticos e prebióticos no mesmo produto resulta num alimento simbiótico, que sugere sinergismo, pois o composto prebiótico age seletivamente favorecendo o crescimento de um organismo probiótico (Devi et al., 2019; Nagaoka, 2018).

Dentre as frutas que apresentam potencial de adição em produtos como iogurte, está o cajá (Spondias Mobin L.), fruta nativa do semiárido nordestino com excelentes características relacionadas ao sabor, aroma e aparência (Gonçalves et al., 2018).

As características sensoriais de alimentos que contém simbióticos têm sido relatadas em produtos como o chocolate, sorvete, gelatina e queijo (Monteiro et al., 2015; Oliveira et al., 2015; Nagaoka, 2018). Porém, é necessário avanço em pesquisas sobre os alimentos fermentados, especialmente aqueles que contém simbióticos, para melhor avaliar as suas propriedades sensoriais. Portanto, objetivou-se com este estudo avaliar as características físico-químicas, microbiológicas e de aceitabilidade de iogurtes probióticos e simbióticos produzidos com cajá (Spondias Mombin L.).

\section{Material e métodos}

Foi utilizado leite esterilizado desnatado (proteína- 6,3 g; lipídeos- $0 \mathrm{~g}$; carboidratos- $9,1 \mathrm{~g}$; fibra alimentar$0 \mathrm{~g}$; VCT- $63 \mathrm{kcal}$; cálcio- $209 \mathrm{mg}$ ) e integral (proteína- 6,0 g; lipídeos- 6,0 g; carboidratos- 9,4 g; fibra alimentar- $0 \mathrm{~g}$; VCT- $115 \mathrm{kcal}$; cálcio- $183 \mathrm{mg}$ ), adquirido no comércio local; fermento misto (Docina $\left.{ }^{\circledR}\right)$ que contém cepas de Lactobacillus delbrueckii subsp. bulgaricus e Streptococcus salivarius subsp. thermophilus 
na proporção de 1:1; fermento misto (Bio-Rich $\left.{ }^{\circledR}\right)$ que contém cepas de Bifidobacterium Bb 12 e Lactobacillus acidophilus LA-5; e frutooligossacarídeo (FOS) (SKL Pharma ${ }^{\circledR}$ ).

Para extração da polpa, o fruto cajá (Spondias mombin L.) foi adquirido na Central de Abastecimento do Estado de Pernambuco (CEASA) e selecionado segundo o grau de maturação, levando em consideração a coloração externa da casca totalmente amarela. Os cajás foram primeiramente lavados em água corrente e posteriormente sanitizados em solução com hipoclorito de sódio a $50 \mathrm{ppm}$ durante 15 minutos. Após higienização, foram processados em despolpadeira (Bonina Compacta) seguindo os princípios adequados de produção de polpa e posteriormente armazenados sob refrigeração a $4{ }^{\circ} \mathrm{C}$ (Lemos et al., 2019).

Os inóculos foram preparados a partir de culturas de bactérias liofilizadas. Foram utilizadas duas culturas concentradas para inoculação direta: uma cultura starter $\left(\right.$ Docina $\left.{ }^{\circledR}\right)$ e outra probiótica (Bio-Rich $\left.{ }^{\circledR}\right)$. Para preparo da cultura mãe, um grama de cada cultura (contendo $1,0 \times 10^{6} \mathrm{UFC} \mathrm{g}^{-1}$ de cada um dos quatro microrganismos) foi inoculada em $1000 \mathrm{~mL}$ de leite de vaca UHT.

Foram utilizados leites de vaca esterilizado, integral e desnatado, acrescidos de $12 \%(\mathrm{p} / \mathrm{v})$ de açúcar cristal refinado. A essa mistura foi adicionada $2 \%$ de cultura mãe (contendo $1 \%$ de cultura starter e $1 \%$ de cultura probiótica), sendo posteriormente incubada a $42{ }^{\circ} \mathrm{C}$ até atingir $\mathrm{pH} 4,6 \pm 0,1$. Para as formulações com características simbióticas adicionou-se $14 \mathrm{~g} / 1000 \mathrm{~mL}$ de FOS. Após a fermentação, as formulações foram acrescidas de $25 \%$ de polpa de cajá e armazenadas sob refrigeração a $4{ }^{\circ} \mathrm{C} \pm 2$ para posteriores análises físicoquímicas e microbiológicas. Na Tabela 1 podem ser observadas as formulações elaboradas.

Tabela 1. Formulações de iogurtes com leite integral e desnatado, probióticos e simbióticos, sabor cajá.

\begin{tabular}{ccccc}
\hline Tipo de leite utilizado & Probiótico & Prebiótico $(\mathbf{1 4} \mathbf{g} / \mathbf{1 0 0 0} \mathbf{~} L)$ & Polpa de cajá $(\mathbf{2 5 \%})$ & Formulações \\
\hline \multirow{2}{*}{ Integral } & $\mathrm{X}$ & $\mathrm{X}$ & $\mathrm{X}$ & $\mathrm{I} 1$ \\
& $\mathrm{X}$ & - & $\mathrm{X}$ & $\mathrm{I} 2$ \\
\hline \multirow{2}{*}{ Desnatado } & $\mathrm{X}$ & $\mathrm{X}$ & $\mathrm{X}$ & $\mathrm{D} 1$ \\
\cline { 2 - 5 } & $\mathrm{X}$ & - & $\mathrm{X}$ & $\mathrm{D} 2$ \\
\hline
\end{tabular}

I1 - iogurte simbiótico com leite integral. I2 - iogurte probiótico com leite integral. D1 - iogurte simbiótico com leite desnatado. D2 - iogurte probiótico com leite desnatado.

A acidez titulável foi medida utilizando solução de hidróxido de sódio $(\mathrm{NaOH})$ a $0,1 \mathrm{~mol} \mathrm{~L}$ e fenolftaleína a $1 \%$ como solução indicadora, expressa em grama ( $\mathrm{g}$ ) de ácido lático/100 g e o pH foi determinado utilizando-se potenciômetro (Quimis, Q799-D2) (Association of Official Analytical Chemists, 2002).

A leitura dos sólidos solúveis expressa $\mathrm{em}^{\circ}$ Brix foi realizada por meio de refratômetro manual (Megabrix, RHB-32ATC) devidamente aferido com água destilada.

As quatro formulações, para garantir a segurança alimentar dos provadores, foram submetidas a análises microbiológicas quanto aos padrões de qualidade (coliformes totais, Escherichia coli, bolores e leveduras, Staphylococcus aureus, Estafilococos coagulase positiva e contagem padrão de bactérias aeróbias) (Association of Official Analytical Chemists, 2002, 2003). A contagem de bactérias lácticas foi realizada conforme American Public Health Association (2001).

A presente pesquisa foi previamente aprovada para coleta dos dados e posteriormente aprovada pelo Comitê de Ética em Pesquisa envolvendo seres humanos do Centro de Ciências da Saúde da Universidade Federal de Pernambuco (CEP/CCS/UFPE No 351/11).

As quatro formulações de iogurtes probióticos e simbióticos sabor cajá foram submetidas à avaliação sensorial por 80 provadores não treinados (61\% mulheres e 39\% homens) com idades entre 19 e 55 anos, em cabines individuais com luz branca artificial. Eles receberam aproximadamente $40 \mathrm{~mL}$ de cada amostra com temperatura entre 4 e $8{ }^{\circ} \mathrm{C}$ em potes de polietileno com capacidade para $50 \mathrm{~mL}$, codificados com números aleatórios de três dígitos, acompanhados de água e bolacha para limpeza do palato (Silva et al., 2019). 
Utilizou-se uma escala hedônica de 9 pontos (referentes aos termos hedônicos 1 - desgostei extremamente a 9 - gostei extremamente) para os atributos: cor, sabor, aroma, textura e qualidade global (Instituto Adolfo Lutz, 2008). Para a análise sobre intenção de compra foi utilizada a escala de 5 pontos ( 1 - jamais compraria a 5 - compraria) (Instituto Adolfo Lutz, 2008). Além disso, foram realizadas perguntas de frequência de consumo, conhecimento dos benefícios relacionados ao consumo de produtos lácteos fermentados.

O índice de aceitabilidade (IA) foi calculado para cada um dos atributos avaliados de acordo com Dutcosky (2013), utilizando a seguinte Equação 1:

IA $(\%)=\mathrm{Y} \times 100 / \mathrm{Z}$

Onde:

$\mathrm{Y}=$ nota média obtida para o produto;

$\mathrm{Z}=$ nota máxima obtida.

A análise estatística dos dados foi realizada através da análise de variância (ANOVA) e do teste de comparação de médias de Duncan $(p<0.05)$.

\section{Resultados e discussão}

Os valores de pH, acidez titulável e sólidos solúveis das formulações estão apresentados na Tabela 2.

Tabela 2. Resultados das análises físico-químicas de iogurtes probióticos e simbióticos sabor cajá.

\begin{tabular}{cccc}
\hline Formulações & $\mathbf{p H}$ & AT $(\mathbf{g}$ de ácido lático/100 g) & SS $\left({ }^{\circ} \mathbf{B r i x}\right)$ \\
\hline I1 & $3,97^{\mathrm{a}}$ & $0,60^{\mathrm{a}}$ & $15,20^{\mathrm{a}}$ \\
\hline D1 & $3,80^{\mathrm{b}}$ & $0,63^{\mathrm{a}}$ & $15,10^{\mathrm{a}}$ \\
\hline I2 & $3,80^{\mathrm{b}}$ & $0,63^{\mathrm{a}}$ & $15,20^{\mathrm{a}}$ \\
\hline D2 & $3,85^{\mathrm{b}}$ & $0,65^{\mathrm{a}}$ & $15,00^{\mathrm{a}}$ \\
\hline
\end{tabular}

Letras minúsculas iguais na vertical não diferem significativamente pelo teste de Duncan ( $p>0,05)$. I1 - iogurte simbiótico com leite integral. I2 - iogurte probiótico com leite integral. D1 - iogurte simbiótico com leite desnatado. D2 - iogurte probiótico com leite desnatado. AT - Acidez Titulável; SS: Sólidos Solúveis.

Quanto ao $\mathrm{pH}$, a formulação I1 teve valor superior às demais, apresentando diferença significativa $(p<0,05)$ (Tabela 2). Porém, os valores de $\mathrm{pH}$ das formulações foram considerados adequados de acordo com a legislação vigente no Brasil para leites fermentos (Brasil, 2007). De acordo com Park et al. (2019), o pH está relacionado à atividade metabólica das bactérias. Assim, durante o processo de fermentação do iogurte, microrganismos do gênero Lactobacillus multiplicam-se em $\mathrm{pH}$ mais baixos comparados aos do gênero Streptococcus. Com isso, o ácido láctico produzido na fermentação favorece a coagulação e formação do iogurte através da desestabilização da caseína.

As formulações não apresentaram diferença significativa $(p>0,05)$ quanto à acidez titulável (g de ácido lático/100 g), estando de acordo com o padrão de identidade e qualidade para leites fermentados (Brasil, 2000), que estabelece valores que variam de 0,6 a 2,0 g de ácido lático/100 g (Tabela 2).

Segundo Silva Filho et al. (2016), as diferenças nos valores de acidez, em distintos produtos, podem estar relacionadas ao tipo e à concentração de cultura láctea utilizada, à atividade desta cultura, ao valor estabelecido para finalizar a fermentação, além do tempo de armazenamento.

Com relação ao teor de sólidos solúveis (SS) das formulações, estas não diferiram estatisticamente $(p>0,05)$, podendo ser atribuído ao igual percentual de sacarose adicionado nas diferentes formulações (Tabela 2). Valores semelhantes foram encontrados no estudo de Miranda et al. (2016), na avaliação de SS em bebidas lácteas probióticas adicionadas de polpa de abacate, em que observaram valores que variaram de 15,6 a 13,33 ${ }^{\circ}$ Brix após 21 dias em armazenamento. 
Considerando o padrão para coliformes a $30{ }^{\circ} \mathrm{C}$ e $45{ }^{\circ} \mathrm{C}$ e bolores e leveduras, não se verificou contaminação destes grupos. Quanto às análises de Escherichia coli, Staphylococcus aureus, Estafilococos coagulase positiva e contagem padrão de bactérias aeróbias, não foi detectada presença destes microrganismos nas formulações analisadas.

Desta forma, podem-se evidenciar boas práticas de fabricação, qualidade da matéria-prima utilizada e condições adequadas de armazenamento para os iogurtes probióticos e simbióticos produzidos com cajá, estando de acordo com os padrões da legislação em vigor (Brasil, 2000).

As contagens de bactérias lácticas totais (Tabela 3) demonstraram valores semelhantes e satisfatórios em todas as formulações, sendo a formulação simbiótica com leite desnatado a que apresentou maior média. Segundo a Instrução Normativa $\mathrm{N}^{\circ} 46$ (Brasil, 2007), a contagem de bactérias lácticas totais (UFC/g) em iogurtes deve apresentar um mínimo de $10^{7}$ ou $10^{6}$ UFC de bifidobactérias/g (quando mencionado o uso de bifidobactérias) durante seu período de validade.

Tabela 3. Média da contagem de bactérias lácticas totais em iogurtes probióticos e simbióticos sabor cajá.

\begin{tabular}{ccccc}
\hline \multirow{2}{*}{ Dia } & \multicolumn{4}{c}{ Formulações (UFC/g) } \\
\cline { 2 - 5 } & I1 & D1 & I2 & D2 \\
\hline 1 & $1,62 \times 10^{7}$ & $1,98 \times 10^{7}$ & $1,89 \times 10^{7}$ & $1,67 \times 10^{7}$ \\
\hline $\begin{array}{l}\text { I1 - iogurte simbiótico com leite integral. I2 } \\
\text { probiótico com leite desnatado. }\end{array}$
\end{tabular}

Fonseca et al. (2014) verificaram a sobrevivência e viabilidade de bactérias lácticas em formulações de iogurtes com cajuí, durante o período de vida útil do produto. Com isso foi observado que a polpa da fruta não apresentou efeitos danosos sobre a viabilidade dos microrganismos Streptococcus e Lactobacillus, mantendo-se dentro do padrão de qualidade para iogurtes, que estabelece valor mínimo aceitável de 7 Log UFC. $\mathrm{g}^{-1}$.

As médias das notas atribuídas pelos provadores não treinados para os diferentes atributos sensoriais estão apresentadas na Tabela 4.

Tabela 4. Médias das notas para atributos sensoriais de iogurtes probióticos e simbióticos sabor cajá.

\begin{tabular}{ccccc}
\hline \multirow{2}{*}{ Atributos } & \multicolumn{4}{c}{ Formulações } \\
\cline { 2 - 5 } & $\mathbf{I 1}$ & $\mathbf{D 1}$ & $\mathbf{I 2}$ & $\mathbf{D 2}$ \\
\hline Cor & $7,85^{\mathrm{a}}$ & $7,77^{\mathrm{a}}$ & $7,81^{\mathrm{a}}$ & $7,70^{\mathrm{a}}$ \\
\hline Sabor & $7,44^{\mathrm{a}}$ & $7,75^{\mathrm{a}}$ & $7,40^{\mathrm{a}}$ & $6,37^{\mathrm{b}}$ \\
\hline Aroma & $8,44^{\mathrm{a}}$ & $8,16^{\mathrm{a}}$ & $7,42^{\mathrm{b}}$ & $7,11^{\mathrm{b}}$ \\
\hline Textura & $7,67^{\mathrm{a}}$ & $7,31^{\mathrm{b}}$ & $7,70^{\mathrm{a}}$ & $6,41^{\mathrm{c}}$ \\
\hline Qualidade Global & $7,56^{\mathrm{a}}$ & $7,64^{\mathrm{a}}$ & $7,44^{\mathrm{a}}$ & $6,45^{\mathrm{b}}$ \\
\hline
\end{tabular}

Letras iguais na horizontal não diferem significativamente pelo teste de Duncan $(p>0,05)$. I1 - iogurte simbiótico com leite integral. I2 iogurte probiótico com leite integral. D1 - iogurte simbiótico com leite desnatado. D2 - iogurte probiótico com leite desnatado. Escala hedônica de 9 pontos (1 - Desgostei extremamente a 9 - Gostei extremamente) utilizada para avaliação dos atributos.

De acordo com o atributo cor, não houve diferença significativa $(p>0,05)$ entre as quatro formulações (Tabela 4). A percepção da cor representa o primeiro contato entre consumidor e produto, depende da composição espectral da luz incidente, das características físicas e espectrais da amostra em relação à absorção, reflexão e transmissão, das condições sob as quais a cor está sendo vista e da sensibilidade do olho. Portanto, as cores possuem capacidade de despertar sensações, provocando reações corporais e psicológicas que refletem na aceitação, rejeição ou indiferença pelo consumidor (Barboza \& Cazal, 2018). 
Para o atributo aroma as formulações adicionadas de FOS (I1 e D1) foram iguais estatisticamente $(p>0,05)$ e apresentaram notas significativamente superiores às formulações probióticas (I2 e D2) $(p<0,05)$ (Tabela 4).

Com relação à textura, as formulações elaboradas com leite integral (I1 e I2) apresentaram médias estatisticamente semelhantes $(p>0,05)$ e mais elevadas do que as formulações elaboradas com leite desnatado (D1 e D2). Estes resultados confirmam a influência da gordura sobre a textura dos alimentos. Sousa et al. (2019) ao avaliarem a aceitabilidade de iogurtes sabor açaí encontraram resultados superiores ao presente estudo: 8,27 (integral) e 7,68 (desnatado). Para os autores, a concentração de gordura influenciou significativamente na formação de gel resistente, diminuindo a capacidade de separação do soro (sinérese) e, consequentemente, houve maior aceitabilidade pelos provadores.

A qualidade global é entendida pelo conjunto relativo à primeira impressão causada pelo produto como um todo, sem representar a média das notas das outras características avaliadas. Das quatro formulações analisadas, três (I1, I2 e D1) apresentaram médias acima de 7,0, não diferindo estatisticamente entre si $(p>0,05)$ (Tabela 4).

Os resultados obtidos para o índice de aceitabilidade das formulações foram: I1 (92,2\%); D1 (94,6\%); I2 $(96,6 \%)$ e D2 $(88,3 \%)$, sendo superiores a $70 \%$. De acordo com Dutcosky (2013), para que um produto seja considerado aceito, em termos de suas propriedades sensoriais, é necessário que obtenha um índice de aceitabilidade de no mínimo 70\%, confirmando, assim, que todas as formulações foram aceitas.

Com relação à frequência de consumo, 71,25\% dos provadores afirmaram consumir produtos lácteos mais de uma vez por semana.

A pesquisa de mercado realizada, descrita como intenção de compra, revelou que as médias das notas foram elevadas para todas as formulações, apresentando resultados favoráveis. As formulações I1, D1 e I2, com médias de 4,23, 4,21 e 4,00, respectivamente, corresponderam na escala a valores entre "Talvez compraria" e "Certamente compraria", seguidas de D2 com 3,29, correspondente a "Talvez compraria, talvez não compraria" a "Talvez compraria".

\section{Conclusões}

As formulações apresentaram resultados satisfatórios quanto aos parâmetros físico-químicos e microbiológicos, coerentes com o tipo de produto em estudo e seguros do ponto de vista higiênico-sanitário.

As contagens de bactérias lácticas totais demonstraram valores adequados, dentro dos parâmetros exigidos pela legislação em vigor.

Ambas as formulações com leite integral (I1 e I2) e a formulação com leite desnatado e FOS (D1) apresentaram resultados superiores quanto ao teste de aceitação e intenção de compra, além de um elevado índice de aceitabilidade, este último para as quatro formulações analisadas.

\section{Referências}

American Public Health Association - APHA. (2001). Compendium of methods for the microbiological examination of foods (1st ed.). Washington: APHA.

Association of Official Analytical Chemists - AOAC. (2002). Official methods of analysis (17th ed.). Washington: AOAC. Association of Official Analytical Chemists - AOAC. (2003). Official methods of analysis (17th ed.). Gaithersburg: AOAC.

Barboza, H. C., \& Cazal, M. M. (2018, outubro 24). Avaliação da influência de características sensoriais e do conhecimento nutricional na aceitação do chá-mate. Brazilian Journal of Food Technology, 21, e2017075. http://dx.doi.org/10.1590/19816723.7517

Brasil. Ministério da Agricultura, Pecuária e Abastecimento - MAPA. (2000, novembro 27). Oficializa os Padrões de Identidade e Qualidade (PIQ) de leites fermentados (Resolução $n^{\circ}$ 5, de 13 de novembro de 2000). Diário Oficial [da] República Federativa do Brasil, Brasília. 
Brasil. Ministério da Agricultura, Pecuária e Abastecimento - MAPA. (2007). Regulamento técnico de identidade e qualidade de leites fermentados (Instrução normativa $n^{\circ}$ 46, de 23 de outubro de 2007). Diário Oficial [da] República Federativa do Brasil (16 p.), Brasília.

Brasil. Ministério da Agricultura, Agência Nacional de Vigilância Sanitária - ANVISA. (2018, julho 26). Resolução Nº 243 de 26 de julho: Dispõe sobre os requisitos sanitários dos suplementos alimentares (100p.). Brasília.

Das, K., Choudhary, R., \& Thompson-Witrick, K. A. (2019). Effects of new technology on the current manufacturing process of yogurt-to increase the overall marketability of yogurt. Lebensmittel-Wissenschaft + Technologie, 108, 69-80. http://dx.doi.org/10.1016/j.Iwt.2019.03.058

Devi, G., Harikrishnan, R., Paray, B. A., Al-Sadoon, M. K., Hoseinifar, S. H., \& Balasundaram, C. (2019). Effect of symbiotic supplemented diet on innate-adaptive immune response, cytokine gene regulation and antioxidant property in Labeo rohita against Aeromonas hydrophila. Fish \& Shellfish Immunology, 89, 687-700. PMid:31002929.

http://dx.doi.org/10.1016/j.fsi.2019.04.036

Dutcosky, S. D. (2013). Análise sensorial de alimentos (4. ed.). Curitiba: Champagnat.

Fonseca, C. M., Boari, C. A., Domingues, P. H. F., Meira, D. P., Fernandes, L. S. F., \& Dumont, M. A. (2014). logurte produzido com cajuí (Anacardium othonianum Rizz). Semina: Ciências Agrárias, 35(4), 1829-1836. http://dx.doi.org/10.5433/16790359.2014v35n4p1829

Gonçalves, N. M., Ferreira, I. M., Silva, A. M. O., \& Carvalho, M. G. (2018). logurte com geleia de cajá (Spondias mombin I.) adicionado de probióticos: Avaliação microbiológica e aceitação sensorial. Revista Brasileira de Higiene e Sanidade Animal, 12(1), 54-63. http://dx.doi.org/10.5935/1981-2965.20180006

Instituto Adolfo Lutz - IAL. (2008). Métodos físico-químicos para análise de alimentos (4. ed.). São Paulo: IAL.

Langa, S., Van Den Bluck, E., Peirotén, A., Gaya, P., Schols, H. A., \& Arqués, J. L. (2019). Application of lactobacilli and prebiotic oligosaccharides for the development of a synbiotic semi-hard cheese. Lebensmittel-Wissenschaft + Technologie, 114, 108361. http://dx.doi.org/10.1016/j.Iwt.2019.108361

Lemos, D. M., Rocha, A. P. T., Gouveia, J. P. G., Oliveira, E. N. A., Sousa, E. P., \& Silva, S. F. (2019). Elaboração e caracterização de geleia prebiótica mista de jabuticaba e acerola. Brazilian Journal of Food Technology, 22, e2018098. http://dx.doi.org/10.1590/1981-6723.09818

Miranda, N. L., Reck, I. M., \& Clemente, E. (2016). Utilização de polpa de abacate em formulações de bebidas lácteas probióticas. Uningá Review, 26(3), 35-39.

Monteiro, R. C. R., Veloso, C. R., Neres, L. S., Lourenço Júnior, J. B., Pacheco, E. A., Abe Sato, S. T., Santos, M. A. S., Nahum, B. S., \& Ribeiro, I. A. (2015). Desenvolvimento e avaliação da qualidade de sorvete de iogurte simbiótico, de leite de búfala enriquecido com polpa de açaí (Euterpe oleracea). Nucleus, 12(2), http://dx.doi.org/10.3738/1982.2278.1162

Nagaoka, S. (2018). Yogurt production. In M. Kanauchi (Ed.), Lactic acid bacteria (Methods in Molecular Biology, No. 1887). New York: Humana Press. Retrieved in 2019, May 23, from https://link.springer.com/book/10.1007\%2F978-1-4939-8907-2

Oliveira, M. C., Santos, E. F., Candico, C. J., Rodrigues, B. M., Hokama, L. M., \& Novello, D. (2015). Elaboração de chocolates com adição de inulina: Análise físico-química e sensorial. Revista UNIABEU, 8(19), 1-16.

Park, Y. W., Oglesby, J., Hayek, S., Aljaloud, S., Gyawali, R., \& Ibrahim, S. (2019). Impact of different gums on textural and microbial properties of goat milk yogurts during refrigerated storage. Foods, 8(5), 169. http://dx.doi.org/10.3390/foods8050169

Silva Filho, W. L. G., Dias, C. S., \& Ribeiro, C F A. (2016). Bebida láctea fermentada com adição de resíduo de industrialização de suco de abacaxi. Revista Tecnologia e Ciência Agropecuária, 10(4), 32-39.

Silva, I. G., Andrade, A. P. C., Silva, L. M. R. S., \& Gomes, D. S. (2019). Elaboração e análise sensorial de biscoito tipo cookie feito a partir da farinha do caroço de abacate. Brazilian Journal of Food Technology, 22, e2018209. http://dx.doi.org/10.1590/1981-6723.20918

Sousa, N. L., Alves, M. S., Gomes, W. C., Zagmignan, A., Silva, L. C. N., Ferreira, L. C., Santos, A. F., \& Coimbra, L. M. P. L. (2019). Elaboração e análise sensorial de iogurte sabor açaí (Euterpe oleracea Mart.). In B. R. S. Silva Neto (Ed.), A produção do conhecimento nas ciências da saúde 2 (pp. 260-269). Ponta Grossa: Atena. http://dx.doi.org/10.22533/at.ed.99919300430. 